\title{
Impact of the Mean Platelet Volume on Muscle-Invasive Bladder Cancer: An Initial Report From a Pioneer Center
}

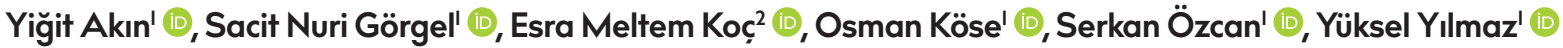 \\ 'Department of Urology, İzmir Katip Çelebi University School of Medicine, İzmir, Turkey \\ ${ }^{2}$ Department of Family Medicine, İzmir Katip C̣elebi University School of Medicine, İzmir, Turkey
}

ORCID IDs of the authors: Y.A. 0000-000I-7627-3476; S.N.G. 0000-000I-7628-I249; E.M.K. 0000-0003-3620-I26I; 0.K. 0000-0003-49I22597; S.Ö. 0000-0002-2459-139X; Y.Y. 0000-0002-0548-9322. Cite this article as: Akın Y, Görgel SN, Koç EM, Köse O, Özcan S, Yılmaz Y. Impact of the Mean Platelet Volume on Muscle-Invasive
Bladder Cancer: An Initial Report From a Pioneer Center. Cyprus J Med Sci 2019; 4(I): 14-8.

\section{BACKGROUND/AIMS}

The mean platelet volume (MPV) is used nowadays to predict the cancer prognosis. As the incidence of muscle-invasive bladder cancer (MIBC) is rising, we aimed to determine the disease-specific survival (DSS) and overall survival (OAS) rates in MIBC using MPV in patients who underwent radical cystectomy.

\section{MATERIAL and METHODS}

This is a retrospective analysis of data from an ongoing bladder cancer project. A total of 168 patients with bladder cancer who underwent cystectomy were enrolled between February 2006 and 2016. A potential prognostic value of MPV was evaluated using the receiver operating characteristic (ROC) curve analysis. We examined the impact of MPV on patients' DSS and OAS. ROC curves were drawn. A p-value $<0.05$ was considered to be statistically significant.

\section{RESULTS}

The mean age was $62.10 \pm 9.26$ years. There were 156 (92.9\%) men and 12 (7.1\%) women. The optimal MPV cutoff value for DSS was $8.37 f L$. The group with a lower MPV showed worse progression with regard to DSS and OAS $(p<0.001)$. Age $(p=0.024), M P V(p=0.00 I)$ were independent prognostic factors for predicting DSS. Additionally age $(p=0.003)$, and MPV $(p<0.001)$ were determined as independent prognostic factors for predicting OAS.

\section{CONCLUSION}

A decreased MPV can be an independent prognostic factor in patients with MIBC. If the MPV is lower than 8.37fL, DSS and OAS may worsen.

Keywords: Bladder cancer, cystectomy, mean platelet volume

\section{INTRODUCTION}

Bladder cancer (BC) is the seventh most common cancer in males (I). In addition, it is the Ilth most common cancer when both genders are considered worldwide (I). The age-standardized annual incidence rate for men and women is $9 / 100.000$ and 2.2/100000, respectively (2). Nearly $75 \%$ of patients with BC are diagnosed at the stage Ta, carcinoma in situ (disease confined to the mucosa), or stage $\mathrm{TI}$ (submucosa). Furthermore, many cases of the patient population ( $\mathrm{Ta}$, $\mathrm{TI}$, and carcinoma in situ) have a high prevalence of a long-term follow-up and have a lower risk of cancer-specific mortality than T2-4 tumors $(3,4)$.

Surgical treatment of muscle-invasive bladder cancer (MIBC) as the radical cystectomy is considered to be standard surgical treatment modality. It is also indicated in those with high-risk and recurrent non-muscle invasive BC (5). The remaining life span depends, of course, on several factors.

On the other hand, platelets play one of the essential roles in human carcinogenesis (6). Thus, the interaction causes their involvement in many malignancies and contributes to the progression (6). The platelet count with the mean platelet volume (MPV) can measure the platelet activation (7). Recent studies suggest that the platelet activation can show a 
significant biological process related to cancer formation and metastasis (8-10). With this in view, some blood tests may help clinicians to predict the process of survival after a radical cystectomy in MIBC.

The MPV, as an early indicator of the platelet activation, is altered in several malignancies; however, there is limited information about using MPV to predict survival of patients with MIBC who underwent radical cystectomy.

In this study, we investigated the impact of MPV on survival in patients with MIBC who underwent radical cystectomy. Moreover, to the best of our knowledge, this is the first study on this issue from our community that is including a high volume patients.

\section{MATERIAL and METHODS}

The present study is a part of an ongoing study that includes a retrospective assessment of the institution's data. The board of Izmir Katip Celebi University approved the study. Signed consent forms were obtained from all patients. There were a total of 168 patients with MIBC who underwent cystectomy between February 2006 and 2016 at our department. The exclusion criteria were having another cancer, irregular follow-up, chronic drug use that could change blood parameters, any hematologic disease, and patients with incomplete transurethral resected bladder cancer.

Briefly, all blood samples were collected from the antecubital veins, after at least 12 hours of fasting, and the same laboratory checked the results. Radical cystectomies were performed I month after transurethral resection bladder tumor (TURBT). The medical data were obtained through the patients' medical records from the urology department and the electronic database of the hospital, and they included patient's age,

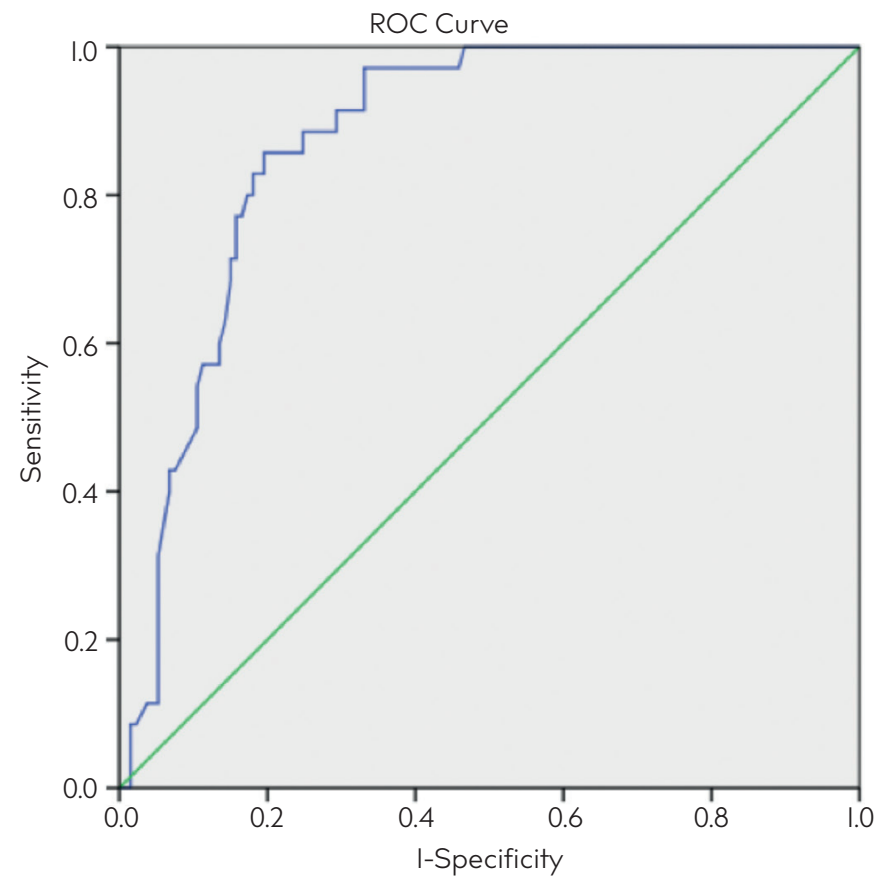

FIGURE I. ROC analysis for disease specific survival for preoperatively measured mean platelet volume gender, the pathological T stage, tumor grade, lymph node metastasis, lymphovascular invasion, white blood cell (WBC) count, and MPV. Laboratory data were collected within I week before radical cystectomy. A histological evaluation of BC was performed according to the World Health Organization classification (II), and BC was staged according to the TNM criteria (12).

Mortality causes were obtained by searching the computer-saved database of the institute. Disease-specific survival (DSS) and overall survival (OAS) were defined as the time from the date of surgery to the date of disease-specific mortality and as the time from the date of surgery to the date of all-cause mortality, respectively.

We used the Statistical Package for the Social Sciences software version 22 (IBM Corp.; Armonk, NY, USA). All variables were examined using visual (histograms, probability plots) and analytical methods (Kolmogorov-Smirnov). A normal or abnormal distribution was determined. The descriptive analyses were used, and the results were presented as means ( \pm standard deviations) and medians (min-max)

An optimal cutoff value of MPV was calculated using the receiver operating characteristic (ROC) curves. The Kaplan-Meier method and log rank test were performed to compare the variables and determine the impact of MPV on patient DSS and OAS. The effect of patient, age, gender, the pathological T stage, tumor grade, lymphovascular invasion, and lymph node involvement were determined by using univariate and multivariate Cox regression hazard models. A 5\% Type I error level was used to obtain statistical significance. The $p$-value $p<0.05$ was accepted as statistically significant.

\section{RESULTS}

There were a total of 159 patients with MIBC who underwent radical cystectomy in this series. The mean age was $62.10 \pm 9.26$ years (range, 37-85). There were 156 (92.9\%) men and 12 (7.1\%) women. The lymphovascular invasion was positive in $5 \mathrm{l}$ patients $(30.4 \%)$. There were 40 (23.8\%) patients at the $\mathrm{TI}$ stage, 43 (25.6\%) patients at the T2 stage, 51 (30.4\%) patients at the T3 stage, and 34 (19.5\%) patients at the T4 stage. The lymph node invasion was determined in 61 (36.2\%) patients. The mean WBC was $8.65 \pm 1.88 \times 10^{\%} / \mathrm{L}$, and the mean MPV was $9.30 \pm 1.96 \mathrm{fL}$. The ROC analysis showed that there was an optimal threshold of MPV for DSS at the level of $8.37 \mathrm{fL}$ (Figure I). This showed us that MPV can estimate the MIBC prognosis with sensitivity and specificity of $91.4 \%$ and of $70.0 \%$, respectively (AUC, 0.873; 95\% confidence interval [CI], 0.820-0.927). Two groups were created according to the MPV levels. There were 7 ( $(42.2 \%)$ patients with $\mathrm{MPV}<8.37 \mathrm{fL}$ and $97(57.8 \%)$ with MPV $\geq 8.37 \mathrm{fL}$.

In the Kaplan-Meier analyses, the group with a decreased MPV showed a worse progression in DSS and OAS ( $p<0.001, p<0.001)$ (Figure 2). The mean follow-up period was $27.59 \pm 26.7$ months (range, I-I30 months), and 36 patients died during the observation period. $95 \% \mathrm{Cl}, 3.5 \mathrm{I5}-91.220 ; \mathrm{p}=0.00 \mathrm{I})$ were used to predict DSS; and age 

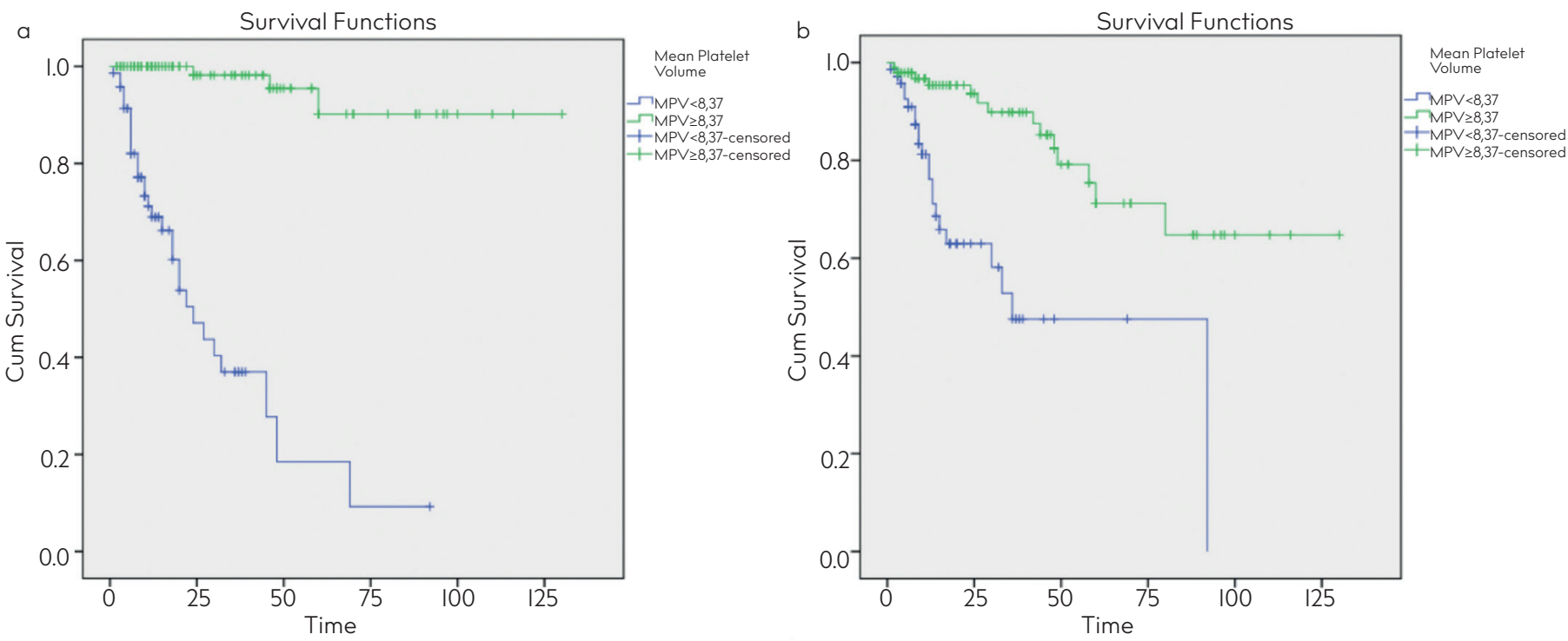

FIGURE 2. a-b. Kaplan-Meier analysis of disease-specific survival according to the mean platelet volume following cystectomy for bladder cancer (a). Kaplan-Meier analysis of overall survival according to the mean platelet volume after cystectomy for muscle invasive bladder cancer (b)

TABLE I. Univariate analyses of various parameters for disease specific survival and overall survival

\section{Parameters}

Age

Gender (female vs. male)

Lymphovascular invasion (negative vs. positive)

Pathological T stage (TI-T2 vs. T3-T4)

Tumor grade (GI vs. G2-G3)

MPV $(\geq 8.37$ vs. $8.37<)$

Lymph node involvement (negative vs. positive)

DSS HR $(95 \% \mathrm{Cl})$

$1.035(0.998-1.073)$

$0.339(0.129-0.888)$

$3.943(1.955-7.951)$

$22.020(6.578-73.715)$

$3.268(0.445-23.971)$

$32.477(9.658-109.210)$

$4.691(2.315-9.502)$

\section{p}

0.066

$0.028^{*}$

$<0.00$ I* $^{*}$

$<0.00$ * $^{*}$

0.244

$<0.00$ I* $^{*}$

$<0.00$ * $^{*}$
OAS HR $(95 \% \mathrm{Cl})$

1.054 (1.016-1.093)

$0.867(0.205-3.664)$

I.54I (0.719-3.306)

$2.293(1.149-4.573$

1.061 (0.324-3.488)

4.852 (2.378-9.898)

$1.670(0.846-3.298)$ p

$0.005^{*}$

0.846

0.266

$0.019 *$

0.922

$<0.00$ I* $^{*}$

$<0.139 *$

DSS: disease specific survival; OAS: overall survival; MPV: mean platelet volume

*Statistically significant $p$-value

(HR, I.055 95\% Cl, I.019-1.093; $p=0.003)$ and MPV (HR 8.03l, 95\% $\mathrm{Cl}, 2.930-22.012 ; \mathrm{p}<0.00 \mathrm{I})$ were used to predict OAS. These were determined as independent prognostic factors, in terms of univariate and multivariate analyses in Cox regression models, respectively (Table I, 2).

\section{DISCUSSION}

There was a statistically significant low MPV level in patients with MIBC who underwent radical cystectomy, just before the operation. The relationship between inflammation and cancer has been identified (13). The MPV is one the markers of activated platelets. Thus, a low MPV level could be regarded as an increased consumption of large platelets during inflammation (14).

Platelets' microparticles and granules are responsible for the platelet-tumor cell interaction, as they contain some growth factors, chemokine, adhesive particles, and coagulation factors (15). Besides, platelets adhere to tumor cells and to the vessel wall after activation (16). These interactions lead to an increased tumor cell survival. Therefore, platelet aggregation to withstand the intravascular shear potency better and armor tumor cells from immune system of host (6). In addition, platelets may play an important role in the cancer progression cascade with an ultimate joint use of mediators and pathways of inflam- mation (17). Moreover, platelets release the transforming growth factor $\beta$ I that induces phenotypic changes of the epithelial to mesenchyme-like transition of tumor cells. Therefore, platelets facilitate their extravasation to distant sites, while metastasis is forming. The activated platelets release secretory factors that support chemokine, photolytic enzymes, and micro particles within the microenvironment to organize the tumor cell invasion (6). These results are also parallel to the current literature indicating that anti-platelet treatment is a part of cancer adjuvant therapies (18). In brief, platelets may play a major role in the tumor process. This was the starting point of our study.

Connolly et al. (19) showed an association between the platelet activities in cancer patients. Stegnet et al. (20) added to their finding and reported the platelet contribution to cancer metastasis. These studies guided us particularly in cancer processes, including cancer cells spreading to organs through blood circulation; platelets are the backbone of malign cells' aggregation $(19,20)$. The platelet activation parameters (soluble P-selectin, soluble CD40 ligand, and platelet factor 4) were determined to be higher in cancer patients than in cancer-free patients (2I, 22). In this manner, we could show that an optimal threshold of MPV for DSS was $8.37 \mathrm{fL}$. These findings are parallel to the findings in the literature above. 


\begin{tabular}{|c|c|c|c|c|}
\hline Parameters & DSS HR $(95 \% \mathrm{Cl})$ & $\mathbf{p}$ & OAS HR $(95 \% \mathrm{Cl})$ & $\mathrm{p}$ \\
\hline Age & $1.039(1.005-1.075)$ & $0.024^{*}$ & $1.055(1.019-1.093)$ & $0.003^{*}$ \\
\hline Female & I (referent) & \multirow[t]{2}{*}{0.815} & I (referent) & \multirow[t]{2}{*}{0.593} \\
\hline Male & $0.890(0.335-2.367)$ & & $1.492(0.344-6.472)$ & \\
\hline Negative & I (referent) & \multirow[t]{2}{*}{0.315} & I (referent) & \multirow[t]{2}{*}{0.728} \\
\hline Positive & $1.527(0.669-3.486)$ & & $0.846(0.330-2.169)$ & \\
\hline \multicolumn{5}{|c|}{ Pathological T stage } \\
\hline TI-T2 & I (referent) & 0.15 & I (referent) & 0.306 \\
\hline \multicolumn{5}{|l|}{ Tumor grade } \\
\hline G2-G3 & $0.305(0.030-3.121)$ & 0.317 & $0.700(0.192-2.549)$ & 0.588 \\
\hline \multicolumn{5}{|c|}{ Lymph node involvement } \\
\hline Negative & I (referent) & \multirow[t]{2}{*}{0.319} & I(referent) & \multirow[t]{2}{*}{0.446} \\
\hline Positive & $1.543(0.657-3.620)$ & & $1.419(0.576-3.492)$ & \\
\hline \multicolumn{5}{|l|}{ MPV } \\
\hline 8.37 or greater & I (referent) & \multirow[t]{2}{*}{$0.001^{*}$} & I (referent) & \multirow[t]{2}{*}{$<\left.0.00\right|^{*}$} \\
\hline Less than 8.37 & 17.907 (3.515-91.220) & & 8.031 (2.930-22.012) & \\
\hline
\end{tabular}

Xin Wang et al. (23) showed that a decreased MPV was associated with the T stage and histology in the Kaplan-Meier analysis, with a poorer overall survival in patients with MIBC. Our results are parallel to theirs. However, our database belongs to a single pioneer center from our community pointing that the results should be repeated in other nationalities. In addition, both the present study and Xin Wang et al. (23) reported a similar finding that activated platelets could play a major role in MIBC. An easily performed blood test including MPV can tell clinicians more in terms of predicting DSS and OSS in MIBC. In another work, Seles et al. (24) similarly reported that a low platelet volume was associated with large tumors, a high Fuhrman grade, sarcomatoid components, histologic tumor necrosis, and vascular invasion. In univariate and multivariate analyses, a small platelet volume was able to correctly predict the renal cell carcinoma recurrence and cancer-specific survival (24).

On the other hand, studies investigating the platelet activity in gastrointestinal cancers indicate the opposite: high MPV levels showed a poor prognosis (25). Nevertheless, according to our study if the preoperative MPV is less than $8.37 \mathrm{fL}$, a decreased DSS and OAS could be determined in patients with MIBC. These are in compliance with the literature.

Our study had some limitations. Its retrospective nature is the first one. The second one are limited MIBC patient numbers. The absence of molecular studies is another limitation. However, our data belong to a single pioneer center, and novel results are supporting the current literature.

The MPV can be measured by a simple blood test before the operation. Results of the test can show clinicians valuable data on DSS and OSS in MIBC. Therefore, clinicians can inform patients more accurately indirectly. Our findings should be examined in future molecular studies.

Considering the above discussion, a decreased preoperative MPV can be an independent prognostic factor in patients with MIBC who underwent radical cystectomy. If the preoperative MPV is less than $8.37 \mathrm{fL}$, DSS and OAS could be worse. However, our results should be confirmed by large and properly designed prospective, randomized trials with molecular studies for revealing the tangible effects of MPV on MIBC.

Ethics Committee Approval: Ethics committee approval was received for this study from the Ethics Committee of Izmir Katip Celebi University School of Medicine (Approval Date: 21.03.2018, Approval Number: IOI).

Informed Consent: Informed consent was obtained from the patients who participated in this study.

Peer-review: Externally peer-reviewed.

Author contributions: Concept - Y.A., S.N.G.; Design - Y.A., S.N.G., O.K.; Supervision - S.Ö., Y.Y.; Resource - S.Ö., S.N.G.; Materials - S.N.G., Y.A., O.K.; Data Collection and/or Processing - S.N.G., Y.A.; Analysis and/or Interpretation - E.M.K., S.Ö.; Literature Search - O.K., E.M.K.; Writing - Y.A., S.N.G.; Critical Reviews - Y.A., S.N.G., Y.Y.

Conflict of Interest: The authors have no conflicts of interest to declare.

Financial Disclosure: The authors declared that this study has received no financial support. 


\section{REFERENCES}

I. Ferlay J, Steliarova-Foucher E, Lortet-Tieulent J, Rosso S, Coebergh JW, Comber $\mathrm{H}$, et al. Cancer incidence and mortality patterns in Europe: estimates for 40 countries in 2012. Eur J Cancer 2013; 49: 1374-403. [CrossRef]

2. Ferlay J, Soerjomataram I, Dikshit R, Eser S, Mathers C, Rebelo M, et al. Cancer incidence and mortality worldwide: sources, methods and major patterns in GLOBOCAN 2012. Int J Cancer 2015; 136: E359-86. [CrossRef]

3. Burger M, Catto JW, Dalbagni G, Grossman HB, Herr H, Karakiewicz $P$, et al. Epidemiology and risk factors of urothelial bladder cancer. Eur Urol 2013; 63: 234-4l. [CrossRef]

4. Steinmaus C, Ferreccio C, Acevedo J, Yuan Y, Liaw J, Durán V, et al. Increased lung and bladder cancer incidence in adults after in utero and earlylife arsenic exposure. Cancer Epidemiol Biomarkers Prev 2014; 23: 1529-38. [CrossRef]

5. Alfred Witjes J, Lebret T, Compérat EM, Cowan NC, De Santis M, Bruins HM, et al. Updated 2016 EAU Guidelines on Muscle-invasive and Metastatic Bladder Cancer. Eur Urol 2017; 7I: 462-75. [CrossRef]

6. Tesfamariam B. Involvement of platelets in tumor cell metastasis. Pharmacol Ther 2016; 157: II2-9. [CrossRef]

7. Kamath S, Blann AD, Lip GY. Platelet activation: assessment and quantification. Eur Heart J 200I; 22: I56I-7I. [CrossRef]

8. Lip GY, Chin BS, Blann AD. Cancer and the prothrombotic state. Lancet Oncol 2002; 3: 27-34. [CrossRef]

9. Nash GF, Turner LF, Scully MF, Kakkar AK. Platelets and cancer. Lancet Oncol 2002; 3: 425-30. [CrossRef]

10. Gay LJ, Felding-Habermann B. Contribution of platelets to tumour metastasis. Nat Rev Cancer 20II; II: 123-34. [CrossRef]

II. Pan CC, Chang YH, Chen KK, Yu HJ, Sun CH, Ho DM. Prognostic significance of the 2004 WHO/ISUP classification for prediction of recurrence, progression, and cancer-specific mortality of non-muscle-invasive urothelial tumors of the urinary bladder: a clinicopathologic study of 1,515 cases. Am J Clin Pathol 2010; 133: 788-95. [CrossRef]

12. Power NE, Izawa J. Comparison of Guidelines on Non-Muscle Invasive Bladder Cancer (EAU, CUA, AUA, NCCN, NICE). Bladder Cancer 2016; 2: 27-36. [CrossRef]

13. Mantovani A, Allavena P, Sica A, Balkwill F. Cancer-related infammation. Nature 2008; 454: 436-44. [CrossRef]
14. Gasparyan AY, Ayvazyan L, Mikhailidis DP, Kitas GD. Mean platelet volume: a link between thrombosis and infammation. Curr Pharm Des 2011; 17: 47-58. [CrossRef]

15. Yan MJ, Jurasz P. The role of platelets in the tumor microenvironment: From solid tumors to leukemia. Biochim Biophys Acta 2016; 1863: 392-400. [CrossRef]

16. Wu H, Fan F, Liu Z, Zhang F, Liu Y, Wei Z, et al. The Angiogenic Responses Induced by Release of Angiogenic Proteins from Tumor Cell-Activated Platelets Are Regulated by Distinct Molecular Pathways. IUBMB Life 2015; 67: 626-33. [CrossRef]

17. Xu XR, Zhang D, Oswald BE, Carrim N, Wang X, Hou Y, et al. Platelets are versatile cells: New discoveries in hemostasis, thrombosis, immune responses, tumor metastasis and beyond. Crit Rev Clin Lab Sci 2016; 53: 409-30. [CrossRef]

18. Mezouar S, Frere C, Darbousset R, Mege D, Crescence L, Dignat-George $\mathrm{F}$, et al. Role of platelets in cancer and cancer-associated thrombosis: experimental and clinical evidences. Thromb Res 2016; 139: 65-76. [CrossRef]

19. Connolly GC, Phipps RP, Francis CW. Platelets and cancer-associated thrombosis. Semin Oncol 2014; 41: 302-10. [CrossRef]

20. Stegner D, Dütting S, Nieswandt B. Mechanistic explanation for platelet contribution to cancer metastasis. Thromb Res 2014; 133(Supp| 2): SI49-57. [CrossRef]

21. Caine GJ, Lip GY, Stonelake PS, Ryan P, Blann AD. Platelet activation, coagulation and angiogenesis in breast and prostate carcinoma. Thromb Haemost 2004; 92: 185-90. [CrossRef]

22. Li L, Li P, Yang YQ, Zhang H, Ai P, Wang F, et al. sCD40L, sPselectin and sICAM-I plasma levels in nasopharyngeal carcinoma. Sichuan Da Xue Xue Bao Yi Xue Ban 2009; 40: 513-6.

23. Xin Wang, Ming-Ming Cui, Yangyang Xu, Li Liu, Ye Niu, Tiemin Liu, et al. Decreased mean platelet volume predicts poor prognosis in invasive bladder cancer. Oncotarget 2017; 8: 68II5-22. [CrossRef]

24. Seles M, Posch F, Pichler GP, Gary T, Pummer K, Zigeuner R, et al. Blood Platelet Volume Represents a Novel Prognostic Factor in Patients with Nonmetastatic Renal Cell Carcinoma and Improves the Predictive Ability of Established Prognostic Scores. J Urol 2017; 198: 1247-52. [CrossRef]

25. Kurt M, Onal IK, Sayilir AY, Beyazit Y, Oztas E, Kekilli M, et al. The role of mean platelet volume in the diagnosis of hepatocellular carcinoma in patients with chronic liver disease. Hepatogastroenterology 2012; 59: 1580-2. 